\title{
Analysis And Capacity Based Earthquake Resistant Design Of Multi Storeyed Building
}

\author{
Amit Kumar ${ }^{1}$, Anant Kumar ${ }^{2}$, Shyam Kishor Kumar ${ }^{3}$, Krishna Murari $^{3}$ \\ 1. Asst. Prof, Department of Civil Engineering, Maulana Azad College of Engineering, Patna (Bihar) \\ 2. P.G Student, Department of Civil Engineering, B.I.T Sindri, Dhanbad, Jharkhand (India) \\ 3. Asst. Prof. Department of Civil Engineering, B.I.T Sindri, Dhanbad, Jharkhand (India)
}

\begin{abstract}
Earthquakes in different parts of the world demonstrated the disastrous consequences and vulnerability of inadequate structures. Many reinforced concrete (RC) framed structures located in zones of high seismicity in India are constructed without considering the seismic code provisions. The vulnerability of inadequately designed structures represents seismic risk to occupants. The main cause of failure of multi-storey reinforced concrete frames during seismic motion is the soft storey sway mechanism or column sway mechanism. The seismic inertia forces generated at its floor levels are transferred through the various beams and columns to the ground. The failure of a column can affect the stability of the whole building, but the failure of a beam causes localized effect. Therefore, it is better to make beams to be the ductile weak links than columns. This method of designing RC buildings is called the strong-column weak-beam design method. If the frame is designed on the basis of strong column-weak beam concept the possibilities of collapse due to sway mechanisms can be completely eliminated. In multi storey frame this can be achieved by allowing the plastic hinges to form, in a predetermined sequence only at the ends of all the beams while the columns remain essentially in elastic stage and by avoiding shear mode of failures in columns and beams. This procedure for design is known as Capacity based design which would be the future design philosophy for earthquake resistant design of multi storey reinforced concrete frames.
\end{abstract}

Keyword: - Seismic analysis, Capacity based design, Staad pro., Modification factor, G+6.

I.

INTRODUCTION

In modern times many multi-storey buildings in cities are in high demand owing to increase in population in one hand and limited available space in the country in general and cities in particular on the other hand. Recent advances in the technology are also encouraging us to go for multi-storey buildings. Such multistorey buildings demand for extra safety while its construction as well as its performance after it has been constructed. Severe earthquakes occur relatively infrequently. Although it is technically possible to Design and construct buildings for these earthquake events, it is generally considered Uneconomical and unnecessary to do so. The seismic design is performed with the Anticipation that the severe earthquake would cause some damage, and a seismic Design philosophy on this basis has been developed over the years. The goal of the seismic design is to limit the damage in a building to an acceptable level. The buildings designed with that goal in mind should be able to resist minor levels of earthquake ground motion without damage, resist moderate levels of earthquake ground motion without structural damage, but possibly with some non-structural damage, and resist major levels of earthquake ground motion without collapse, but with more structural as well as non-structural damage. As the foregoing discussion indicates, earthquake resistant design of buildings is based on the concept of acceptable levels of damage under one or more events of Specified intensity. The acceptable level of damage is related to the performance objective for the building. Ideally the performance should be specified as an acceptable integrated probability of the building exceeding certain limit states during the entire spectrum of earthquake events that the building is likely to experience. Because Of the complexity involved in specifying an integrated probability, requirements are often limit to one or more events of specified intensity. For example, the objective may be specified in the form of a requirement that the building is fully operational with little or no damage during an earthquake.

\section{EXPERIMENTAL PROGRAM}

Capacity Design is a concept or a method of designing flexural capacities of critical member sections of a building structure based on a hypothetical behavior of the structure in responding to seismic actions. This hypothetical behavior is reflected by the assumptions that the seismic action is of a static equivalent nature increasing gradually until the structure reaches its state of near collapse and that plastic hinging occurs simultaneously at predetermined locations to form a collapse mechanism simulating ductile behavior. The actual behavior of a building structure during a strong earthquake is far from that described above, with seismic 
actions having a vibratory character and plastic hinging occurring rather randomly. However, by applying the Capacity Design concept in the design of the flexural members of the structure, it is believed that the structure will possess adequate seismic resistance, as has been proven in many strong earthquakes in the past.

\section{CAPACITY BASED DESIGN:}

Capacity Design is a concept or a method of designing flexural capacities of critical member sections of a building structure based on a hypothetical behavior of the structure in responding to seismic actions. This hypothetical behavior is reflected by the assumptions that the seismic action is of a static equivalent nature increasing gradually until the structure reaches its state of near collapse and that plastic hinging occurs simultaneously at predetermined locations to form a collapse mechanism simulating ductile behavior. The actual behavior of a building structure during a strong earthquake is far from that described above, with seismic actions having a vibratory character and plastic hinging occurring rather randomly. However, by applying the Capacity Design concept in the design of the flexural members of the structure, it is believed that the structure will possess adequate seismic resistance, as has been proven in many strong earthquakes in the past.

A feature in the Capacity Design concept is the ductility level of the structure, expressed by the displacement ductility factor or briefly ductility factor. This is the ratio of the lateral displacement of the structure due to the Design Earthquake at near collapse and that at the point of first yielding.

The basic of capacity based design lies on strong column and weak beam concept. The seismic inertia forces generated at its floor levels are transferred through the various beams and columns to the ground. The correct building components need to be made ductile. The failure of a column can affect the stability of the whole building, but the failure of a beam causes localized effect. Therefore, it is better to make beams to be the ductile weak links than columns. This method of designing RC buildings is called the strong-column weakbeam design method.

Basic steps for capacity based design:

1. Design loads i.e. dead loads, live loads and earthquake loads are calculated.

2. Seismic analysis of the frame for all load combination specified in IS 1893 (Part

I):2002 are done.

3. Members are designed (as per IS 456:200) for maximum forces obtained from all load combinations. Beams are designed for maximum sagging and maximum hogging moments. Provided reinforcements are calculated following the norms given in code.

4. The flexural capacities of the beams under sagging and hogging condition for the provided reinforcements are calculated.

5. The flexural capacity of columns at a joint is compared with actual flexural capacity of joining beams. If the sum of capacities of columns is less than the sum of capacities of beams multiplied by over strength factor, the column moments should be magnified by the factor (moment magnification factor) by which they are lacking in moment capacity over beams. If the sum of the column moments is greater than sum of beam moments, there is no need to magnify the column moments.

6. Columns are designed for the revised moments and the axial force coming on it from the analysis.

7. Shear capacity of beams are calculated on the basis or their actual moment capacities and shear reinforcements are calculated.

8. Similarly shear capacity of column is calculated on the basis of magnified moment capacities. Then the columns are designed for shear.

\section{ANALYSIS OF 3D-RC FRAME BUILDING DATA USING FOR STAAD-PRO}

A G+6 Building is taken for analysis. The salient features of the building are:

(1) Type of structure: -

(2) Seismic Zone:

(3) Type of soil: -

(4) No of stories: -

(5) Imposed load: -

(6) Location: -

(7)Floor finish: -
Multi-story rigid joint frame.

II

Medium soil type (as per IS 1893 (part-1))

$\mathrm{G}+6$.

$3.0 \mathrm{KN} / \mathrm{M} 2$ at typical floor

$1.5 \mathrm{KN} / \mathrm{M} 2$ at terrace level only.

Ranchi city.

$1.0 \mathrm{KN} / \mathrm{M} 2$ 
(8) Terrace: -

(9) Earthquake load: -

(10) Depth of slab: -

(11)Material: -

(12) Unit weight of R.C.C:-

(13) Size of beam: -

(14) Size of column: -

(15) Unit weight of Masonry: -

(16) Clear cover of Beam: -

(17) Clear cover of column: -

(18)Wall Thickness: -

\section{$1.0 \mathrm{KN} / \mathrm{M} 2$}

As per IS 1893 (part-1) 2002.

$120 \mathrm{~mm}$.

M-25 concrete and Fe 500 steel.

$25 \mathrm{KN} / \mathrm{M} 3$.

$300 \times 500 \mathrm{~mm}$ All floors.

$400 \times 400 \mathrm{~mm}$ All Floors But

$500 \times 500 \mathrm{~mm}$ Ground Floor.

$20 \mathrm{KN} / \mathrm{m} 3$.

$25 \mathrm{~mm}$.

$25 \mathrm{~mm}$.

$250 \mathrm{~mm}$.

\subsection{Analysis of 3D-RC frame:}

Multi storied RC Frame

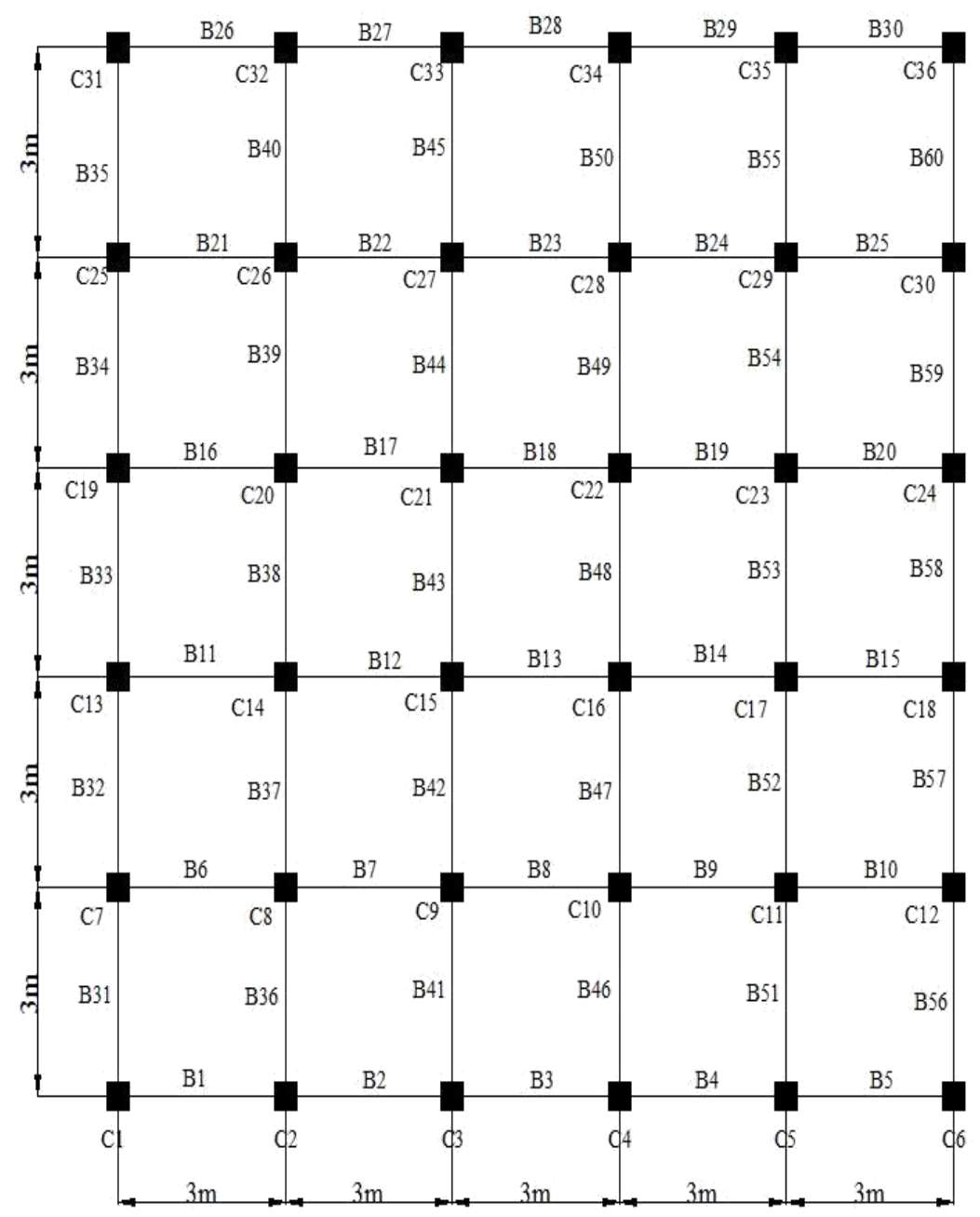

PLAN 


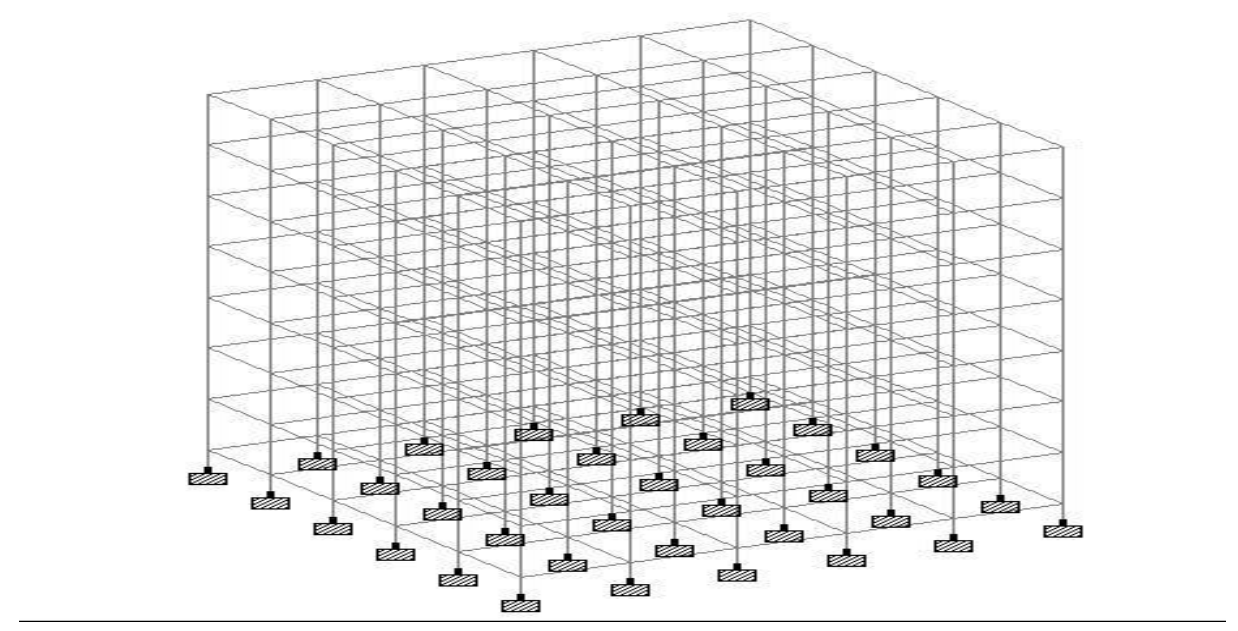

\section{Geometry of the Building:}

The general layout of the building is shown in Figure 1. At ground level, the floor beams FB are not provided, since the floor directly rests on ground (earth filling and 1:4:8 c.c. at plinth level) and no slab is provided. The ground beams are provided at $100 \mathrm{~mm}$ below ground level. The numbering of the members is explained as below.

\section{Storey number}

Storey numbers are given to the portion of the building between two successive grids of beams. For the example building, the storey numbers are defined as follows:

Portion of the building Storey no.

Foundation top -

Ground beams -

First Floor -

Second floor -

Third floor -

Fourth floor -

Fifth floor -

\author{
Ground floor 1 \\ First floor 2 \\ Second floor 3 \\ Third floor 4 \\ Fourth floor 5 \\ Fifth floor 6 \\ Terrace 7
}

Column number:

In the general plan of Figure 1, the columns from $\mathrm{C} 1$ to $\mathrm{C} 36$ are numbered in a convenient way from left to right and from upper to the lower part of the plan. Column C5 is known as column C5 from top of the footing to the terrace level. However, to differentiate the column lengths in different stories, the column lengths are known as 105, 205, 305, 405, 505, 605 and 705 [Refer to Figure 2(b)]. The first digit indicates the storey number while the last two digits indicate column number. Thus, column length 605 means column length in sixth storey for column numbered $\mathrm{C} 5$. The columns may also be specified by using grid lines.

\section{Main beams number:}

Beams, which are passing through columns, are termed as main beams and these together with the columns form the space frame. The general layout of Figure 1 numbers the main beams as beam B1 to B60 in a convenient way from left to right and from upper to the lower part of the plan. Giving 90o clockwise rotation to the plan similarly marks the beams in the perpendicular direction. To floor-wise differentiate beams similar in plan (say beam B5 connecting columns C5 and C6) in various floors, beams are numbered as 1005, 2005, 3005, and so on. The first digit indicates the storey top of the beam grid and the last three digits indicate the beam number as shown in general layout.

Thus, beam 4007 is the beam located at the top of 4th storey whose number is B7 as per the general layout. Gravity Load calculations: Unit load calculations:

Assumed sizes of beam and column sections are: Columns: $400 \times 400$ at all typical floors 
Area, $A=0.16 \mathrm{~m} 2, I=0.00213 \mathrm{~m} 4$. Columns: $500 \times 500$ below ground level Area, $A=0.25 \mathrm{~m} 2, I=0.005208$ m4. Main beams: $300 \times 500$ at all floors Area, $A=0.15 \mathrm{~m} 2, I=0.003125 \mathrm{~m} 4$.

(A) Member self- weights:-(1)Slab at terrace level:-

$$
\mathrm{DL}+\mathrm{LL}
$$

Self-weight of slab

Floor Finish

Terrace Finish

Live Load

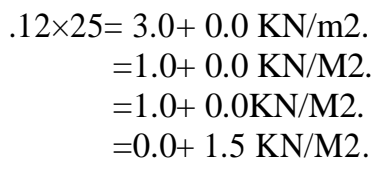

Total $=5.0+1.5 \mathrm{KN} / \mathrm{M} 2$.

(2) Slab at typical floor level:-

Self-weight of slab $-0.12 \times 25=3.0+0.0 \mathrm{KN} / \mathrm{M} 2$

Floor finish $=1.0+0.0 \mathrm{KN} / \mathrm{M} 2$.

Live Load $=0.0+3.0 \mathrm{KN} / \mathrm{M} 2$.

Total

(3) Beams :-

(All Floors)

Main Beams $-0.300 \times 0.500 \times 25=3.75 \mathrm{KN} / \mathrm{M} 2$.

(4) Columns:-

Below Ground level: - Above ground level: - Floor height of column :-Floor Column self-weight:-

$0.500 \times 0.500 \times 25=6.25 \mathrm{KN} / \mathrm{M} 2.0 .400 \times 0.400 \times 25=4.00 \mathrm{KN} / \mathrm{M} 2 .(3.0-0.5)=2.5 \mathrm{~m} .4 .00 \times 2.5=10.0 \mathrm{KN}$.

(5) Peripheral brick walls $250 \mathrm{~mm}$ thick

And 2.5m height floor level.

$0.250 \times 2.5 \times 20=12.5 \mathrm{KN} / \mathrm{M}$

Terrace parapet walls: $-0.250 \times 1.0 \times 20=5 \mathrm{KN} / \mathrm{m}$.

(B)Columns and Beams gravity load:-

(1) Terrace Level:-

Floor beam:-

From slab: $3 \times(5.0+1.5)=15.0+4.5 \mathrm{KN} / \mathrm{M} 2$.

Self weight: $=3.0+0.0 \quad \mathrm{KN} / \mathrm{M} 2$.

Total

$$
=18.0+4.5 \mathrm{KN} / \mathrm{M} 2 \text {. }
$$

All Main beam: - (External),-(B-1, B-2, B-3, B-4, B-5, B-26, B-27, B-28, B-29, B-30)

From slab: -

Parapet: -

Self-weight:-
$3 / 2 \times(5.0+4.5)=7.5+2.25 \mathrm{KN} / \mathrm{M} 2$.

$=5.0+0.0 \mathrm{KN} / \mathrm{M} 2$.

$=3.75+0.0 \mathrm{KN} / \mathrm{M} 2$. 
Column Loads are for External column.

$(\mathrm{C}-1, \mathrm{C}-6, \mathrm{C}-31, \mathrm{C}-36) \quad 3 / 2 \times(16.25+2.25)=24.375+3.375 \mathrm{KN} / \mathrm{M} 2$.

Internal column: - C-2, C-3, C-4, C-5, C-32, C-33, C-34, C-35.

$\overline{3 / 2 \times(16.25+2.25)}=24.375+3.375 \mathrm{KN} / \mathrm{M} 2$.

All main beams (Internal):- (B-6,B-7,B-8,B-9,B-10,B-11,B-12,B-13,B-14,B-15,B-16,B-17,B-18,B-19,B-20,B-

21,B-22,B-23,B-24,B-25)

From slab

$3 / 2 \times(5.0+1.5)$

$=7.5+2.25 \mathrm{KN} / \mathrm{M} 2$.

Self-weight of beam

$=3.75+0.0 \mathrm{KN} / \mathrm{M} 2$.

Total

$=11.25+2.25 \mathrm{KN} / \mathrm{M} 2$.

Columns load: $3 / 2 \times(11.25+2.25) \times 2=33.75+6.75 \mathrm{KN} / \mathrm{M} 2$.

Main beams:- B-31,B-32,B-33,B-34,B-35,B-56,B-57,B-58,B-59,B60.

From slab: -

$3 / 2 \times(5.0+1.5)$

$=7.5+2.25 \mathrm{KN} / \mathrm{m} 2$.

Parapet walls: -

$=5.0+0.0 \mathrm{KN} / \mathrm{M} 2$.

Self-weight:-

$=3.75+0.0 \mathrm{Kn} / \mathrm{M} 2$.

Total

$=16.25+2.25 \mathrm{KN} / \mathrm{M} 2$.

Column loads:- C-1,C-6,C-31,C-36,C-2,C-3,C-4,C-5,C-32,C-33,C-34,C-35

(External) $\quad 3 / 2 \times(16.25+2.25)=24.375+3.375 \mathrm{KN} / \mathrm{M} 2$.

(Internal) $\quad 3 / 2 \times(16.25+2.25) \times 2=48.75+6.75 \mathrm{KN} / \mathrm{M} 2$.

Main beams:(B-36,B-37,B-38,B-39,B-40,B-41,B-42,B-43,B-44,B-45,B-46,B-47,B-

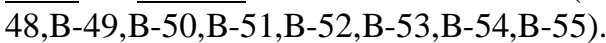

From Slab: -

Self-weight:-
$3 / 2 \times(5.0+1.5)=7.5+2.25 \mathrm{KN} / \mathrm{M} 2$ $=3.75+0.0 \mathrm{KN} / \mathrm{M} 2$.

Total $=11.25+2.25 \mathrm{KN} / \mathrm{M} 2$.

Column loads: - (ALL)

External

Internal
$3 / 2 \times(11.25+2.25)$

$3 / 2 \times(11.25+2.25) \times 2=33.75+6.75$
$=16.875+3.375 \mathrm{KN} / \mathrm{M} 2$. $\mathrm{KN} / \mathrm{M} 2$.

\section{CONCLUSION}

1. Capacity based earthquake resistant design is futuristic approach to design of reinforced concrete structures especially for multi-bay multi storied reinforced concrete buildings.

2. This concept is to restrict the formation of plastic hinges in the beams only hence collapse occurs through the beam mechanism only, which localize the failure and hence leads to less destruction and loss of lives.

3. Collapse due to sway mechanism can cause failure of a storey or whole frame. As its approach is to eliminate sway mechanism by making columns stronger than beams, this method is very effective in design of soft-storey frames.

4. This method also eliminates the possibility of shear mode of failure (which is brittle by nature hence failure occurs suddenly) by making shear capacity of elements more than their moment capacity.

5. Compared with the conventional design methods for earthquake resisting structures although this method is little costlier but is more effective in resisting the earthquake forces.

6. This method of design is more realistic because the calculations are based on provided reinforcement and the over strength of the structure which takes into account the reserve strength beyond elastic limit.

7. As the building can be reused after minimum repair after occurrence of earthquake. 


\section{REFERENCES}

[1] I.S. 1893, "Criteria for Earthquake Res Provisions and BuildingsBureauofIndian Standards(Fifth,2002. Revision)

[2] I.S.456, "Plain - Codeand ReinforofBureauPracoftice",edIndianConcre Standards, 2000.

[3] I.S 13920, "Ductile Detailing of Reinforcement and Seismic Forces-Code of BureauPractice",of IndianStandards, 1993.

[4] SP 16, "Design AidsBureauforofIndianReinforcedStandards,1980. Con

[5] Agarwal Pankaj and Shrikhande Manish, "Ear structures", Prentice Hall of India.

[6] EERI, "Bhuj, India Earthquake of January, Earthquake spectra, supplement to Vol. 18, July 2002.

[7] Goel, R.K., "Performance of Building durin Earthquake", Earthquake Engineering Res

[8] Paulay T. and Priestley M.J.N., "Sei Masonry Buildings"

[9] Penils, G.G and Kappors "Earthquake-Resistant concreteE\&FN str $S P O N$, an imprint of Chapman \& Hall, 1997

[10] WangadinataCapacitydesign, Wa concept" to ensure seismic resistance of building structure" National conference on Earth Technology Bandung, Nov. 4-5. 1999

[11] 11. C.V.R.-MurtyBMTPC “IITK,„Earthquake tips learnin construction“-2005. sept 